$12-1-2019$

\title{
An Individual-Carcass Model for Quantifying Bacterial Cross- Contamination in an Industrial Three-Stage Poultry Scalding Tank
}

\author{
Zachary McCarthy \\ York University, zjm@yorku.ca \\ Ben Smith \\ Public Health Agency of Canada \\ Aamir Fazil \\ Public Health Agency of Canada \\ Shawn D. Ryan \\ Cleveland State University \\ Jianhong Wu \\ York University \\ Follow this and additional works at: https://engagedscholarship.csuohio.edu/scimath_facpub \\ ipraxtofage fortadditional authorsns \\ How does access to this work benefit you? Let us know! \\ Publisher's Statement \\ https://doi.org/10.1016/j.jfoodeng.2019.05.013
}

\section{Repository Citation}

McCarthy, Zachary; Smith, Ben; Fazil, Aamir; Ryan, Shawn D.; Wu, Jianhong; and Munther, Daniel, "An Individual-Carcass Model for Quantifying Bacterial Cross-Contamination in an Industrial Three-Stage Poultry Scalding Tank" (2019). Mathematics Faculty Publications. 295.

https://engagedscholarship.csuohio.edu/scimath_facpub/295

This Article is brought to you for free and open access by the Mathematics and Statistics Department at EngagedScholarship@CSU. It has been accepted for inclusion in Mathematics Faculty Publications by an authorized administrator of EngagedScholarship@CSU. For more information, please contact library.es@csuohio.edu. 


\section{Authors}

Zachary McCarthy, Ben Smith, Aamir Fazil, Shawn D. Ryan, Jianhong Wu, and Daniel Munther 


\title{
An individual-carcass model for quantifying bacterial cross-contamination in an industrial three-stage poultry scalding tank
}

\author{
Zachary McCarthy ${ }^{\mathrm{a}, \mathrm{b}, *}$, Ben Smith ${ }^{\mathrm{d}}$, Aamir Fazil ${ }^{\mathrm{d}}$, Shawn D. Ryan ${ }^{\mathrm{c}}$, Jianhong Wu ${ }^{\mathrm{a}, \mathrm{b}}$, \\ Daniel Munther \\ ${ }^{a}$ Laboratory for Industrial and Applied Mathematics, York University, Toronto, ON, Canada \\ ${ }^{\mathbf{b}}$ Department of Mathematics and Statistics, York University, Toronto, ON, Canado \\ 'Department of Mathematics, Cleveland State University, Cleveland, OH, USA

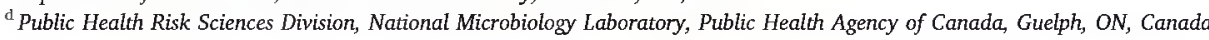

\section{Introduction}

Foodborne illness is a major public health concern and economic burden to the world. Of an estimated 582 million cases of foodborne illness, 96 million cases are caused by Camyplobacter spp. (Kirk et al., 2015 ) including 27,738 deaths. While most cases attributed to Campylobacter spp. are diarrheal, more severe events such as Guillain-Barre syndrome are also associated with Campylobacter spp. infections. An estimated 20-150 cases are reported per 100,000 people in industrialized nations each year (Christine et al., 2008). High prevalence and counts of Campylobacter on retail poultry products continue to pose a threat to consumers (MüllnerJulie et al., 2010; Suzuki and Yamamoto, 2009 ). In addition, it is estimated that $24 \%-46 \%$ of processors will not pass 2015 FSIS-USDA Campylobacter performance standards for chicken products (Food Safety US Department of Agriculture and Inspection Service, 2015).
Poultry raised on the farm are transported to the slaughterhouse and then passed on to retail and consumer markets. Foodborne pathogens such as Campylobacter and Salmonella can persist on birds throughout this "farm-to-fork" process, resulting in contaminated poultry products. The poultry slaughterhouse is a site of concern with regard to the possible spread, growth, and persistence of these pathogens. In particular, the World Health Organization has declared the poultry scalding, chilling, defeathering, and evisceration processes as sites of major crosscontamination and hence are of key importance (FAO/WHO, 2009). To assist with global efforts in reducing the burden of foodborne disease, we proceed using techniques of mathematical modeling to study pathogens levels in the processing plant.

Here we investigate the high-speed industrial scalding stage where carcasses are hung on a processing line and pulled through heated "scald water". The scald water thermally inactivates pathogens; however, it is also a medium for which bacteria may transfer between 
carcasses. The current state-of-the-art mathematical models describing poultry scalding are designed to predict pathogen levels in a single-pass scald system; however, modern scalding systems are comprised of three scalding tanks which broilers pass through sequentially (Osiriphun et al., 2012; McCarthy et al., 2018). These existing mathematical modeling works quantify average bacteria levels over all carcasses in the scalding tank for mathematical and computational convenience.

In this work, we adopt a mathematical model quantifying pathogen levels on each carcass in the scalding tank. There are several advantages of this individual-carcass modeling approach over previously used averaging approaches. National government performance standards for Campylobacter and Salmonella are in terms of individual carcass pathogen levels, hence our modeling framework may be of use to industrial processors and policy-makers (Food Safety US Department of Agriculture and Inspection Service, 2015). Pathogen levels on each carcass varies considerably thus this is a natural step in moving toward model realism. Second, with such a model many different scenarios may be weighed in terms of the risk they pose in terms of individual carcass contamination and carcass-to-carcass transmission. One key advantage is that we may quantify the effects of cross-contamination directly, subject to various senarios. This was an open problem and strong limitation of existing models posed previously (McCarthy et al., 2018).

The objectives of this work are to develop, parametrize, and validate a mathematical model describing the transfer and inactivation dynamics of pathogens on individual carcasses in a three-stage scalding tank. In particular, we aim for this modeling framework to be amenable to integration in Quantitative Microbial Risk Assessment (QMRA) models and have the capacity to weigh various Hazard Analysis and Critical Control Point (HACCP) measures. Long-term goals in this series include the integration of causal, mechanistic models of this form into a complete farm-to-fork QMRA framework. In this work, we provide details of model development; parametrize the model according to specific pathogen $C$. jejuni; and provide forward validation against industrial processing data. We also illustrate how the model may be applied using configurations for a specific industrial poultry processor in Canada.

\section{Model development: an individual-carcass model}

We develop an individual-carcass model (ICM) for describing the bacteria transfer and inactivation in a modern three-stage scalding tank. The formulation we present is similar in scope to an existing model describing the contamination dynamics in a poultry chilling tank (McCarthy et al., 2017). We also note that this model may be classified more generally as an individual-based model, where each carcass represents an individual. We then apply the scald model to a specific strain of Campylobacter ( $C$. jejuni); however, the formulation here may be adapted to model for other mesophilic pathogens such as Escherichia coli and $S$. Typhimirium. The model developed herein quantifies bacteria levels on each carcass passing through a three-stage scalding tank and also bacteria levels in the water of each successive scald tank. During the residence time of carcasses in each scald tank, there is opportunity for transfer (carcass-to-water and vice versa) and thermal inactivation of bacteria. However, we assume that there is no physical contact between carcasses in the tank, hence there is no direct route for bacterial cross-contamination. A key feature of this model is that cross-contamination at the individual level can be investigated.

\subsection{Mechanisms for transfer and inactivation}

Contaminated carcasses enter the scald tank with pathogens attached to their skin and feathers. While the carcasses move through scalding tanks, pathogens shed into the scald water as a result of turbulence, shear forces, and diffusion. Heated scald water thermally inactivates bacteria attached to the carcasses and in the scald water. These basic mechanisms were studied in models previously (McCarthy et al., 2018; Osiriphun et al., 2012). One objective of this work is to quantify the effects of cross-contamination or carcass-to-carcass transmission directly, hence an additional feature of the model we develop is considering bacterial attachment from scald water to carcasses. In other words, we shift directions from a qualitative view to a more quantitative view. This approach is closer to the actual dynamics seen in the scald tank.

\subsection{Modeling approach}

We denote the bacteria level on the $i^{\text {th }}$ carcass as $C_{i}$ colony forming units (CFU), which is subject to change while the carcass resides in each of the three scald tanks. We denote the time for which the $i^{\text {th }}$ carcass enters scald tank 1 as $t_{1}^{1}$ and carcasses have a dwell time of $t_{s}^{1}, t_{s}^{2}, t_{\mathrm{v}}^{3}$ in each successive scald tank. Therefore the $i^{\text {th }}$ carcass leaves the first scald tank at time $t_{i}^{1}=t_{i}^{1}+t^{1}$. We also account for the transition time between scald tanks. That is, the $i^{\text {th }}$ bird enter scald tank 2 a short time $\varepsilon$ after exiting scald tank 1 and so we have $t_{i}^{2}=i_{i}^{1}+\varepsilon$. Finally, the $i^{\text {th }}$ bird passes through all three scald tanks at time $i_{1}^{3}=t_{1}^{3}+t_{s}^{3}$. In other words, we assume for $t_{1}^{1} \leq t \leq i_{1}^{3}$ the carcasses are subject to bacteria transfer and inactivation.

Carcass surface inactivation rate $S_{i}^{j}$ Denote the rate at which bacteria are thermally inactivated on the surfaces of carcasses by $S_{i}^{j}$. Here the indices $i, j$ refer to the inactivation rate on the $i^{\text {th }}$ carcass residing in the $j^{\text {th }}$ scald tank, respectively.

$S_{i}^{\prime}=\left\{\begin{array}{ll}S_{j} & t_{i}^{j} \leq t \leq \hat{t}_{i}^{j} \\ 0 & \text { otherwise }\end{array}\right.$ for $j=1,2,3$.

The pathogen killing potential on carcass surfaces has been shown experimentally to depend on chlorine levels (Yang et al., 2001). Hence we consider the inactivation on carcass surfaces due to the addition of chlorine, and denote this by rate constant $h_{S}$. In other words, we model the total rate of chlorine inactivation on carcass $C_{i}$ by the term $h_{S} C_{i}$.

Shed rate from carcasses to scald water $k_{i}^{j}$ Each broiler carcass in the scald tanks is subject to turbulence in the form of aeration and shear forces. As a result, bacteria on the surface of carcasses are shed into the water. Here we consider some fixed rate of bacteria shedding, $k_{i}^{j}$ (1/ min). Here, the indices $i, j$ refer to shedding of the $i^{\text {th }}$ carcass in $j^{\text {th }}$ scald tank, ensuring that shedding only occurs when the carcass is in the $j^{\text {th }}$ scalding tank. We consider a uniform bacterial shed rate $k$ across all three scald tanks.

$k_{i}^{j}=\left\{\begin{array}{lc}k & t_{i}^{j} \leq t \leq \hat{t}_{i}^{j} \\ 0 & \text { otherwise }\end{array}\right.$

We also consider the attachment of pathogens in scald water to carcasses at some constant rate $\beta(1 / \mathrm{min})$. We assume that the amount of attachment to carcass skins is proportional to the current bacteria levels in the scald water as justified in (McCarthy et al., 2018). As a result of turbulence from counterflow, aeration, and carcass mass moving through the scald tank we assume that shedding and attachment are uniform in all scald tanks. Hence the term $10^{3} T_{V} \beta_{i}{ }^{j} W_{i}$ represents the attachment of bacteria on carcass $i$ from scald tank $j$. The factor $10^{3}$ represents a unit conversion from milliliters to liters.

$\beta_{i}^{\prime}=\left\{\begin{array}{lc}\hat{\beta} & t_{i}^{j} \leq t \leq t_{i}^{j} \\ 0 & \text { otherwise }\end{array}\right.$ for $j=1,2,3$

From these mechanisms described above for bacterial surface thermal inactivation, shedding, and attachment from scald water, we have the following equation governing pathogen levels of each carcass $C_{i}$.

$$
C_{i}{ }^{*}=\left\{\begin{array}{cc}
-\left(k_{i}^{1}+S_{i}^{1}+h_{S}\right) C_{i}-\left(k_{i}^{2}+S_{i}^{2}+h_{S}\right) C_{i}-\left(k_{i}^{3}+S_{i}^{3}+h_{S}\right) C_{i} & \\
+10^{3} T_{V}\left(\beta_{i}^{1} W_{1}+\beta_{i}^{2} W_{2}+\beta_{i}^{3} W_{2}\right) & t_{i}^{1} \leq t<\hat{t}_{i}^{3} \\
0 & \text { otherwise }
\end{array}\right. \text { or }
$$

$i=1, \ldots, N$. 
Scald water contamination and inactivation dynamics Here we aim to capture the contamination dynamics of bacteria in scald water. Let $W_{j}$ $(\mathrm{CFU} / \mathrm{ml})$ denote the bacteria concentration in scald water in scald tank $j$. Bacteria finds its way into the scald water in each tank by means of shedding from resident carcass surfaces (skin and feathers). As a result of the thermal sensitivity of foodborne pathogens in temperature ranges relevant to scalding, we consider a rate of thermal inactivation $I_{w}$ in the scald water (McCarthy et al., 2018).

Also, organic material (excreta, blood, fat, proteins, etc.) in each successive scald tank decreases (Cason et al., 1999). This reduced protection from organics results in higher kill rates in the latter stage tanks. In other words, bacteria is less protected from organic material. The parameter $\alpha$ is the percent increase of kill rate in scald water from these reduced organic material levels. We therefore consider a baseline kill rate in the first tank $\left(\alpha_{1}=0\right)$, so that $\left(1+\alpha_{1}\right) I_{w}=I_{w}$. Reduced organic load in the latter tanks enhances the effective thermal kill rate $\left(\alpha_{2}, \alpha_{3}>0\right)$. To illustrate note that $\left(1+\alpha_{2}\right) I_{w}>I_{w}$ and also $\left(1+\alpha_{3}\right) I_{w}>I_{w}$. Similarly, we consider a fractional increase of effective bacterial kill rate by the addition of chlorine in scald water by $h_{w}$ in tanks $j=1,2.3$. Lastly, in each tank there is clean water inflow and scald water outflow at rate $g \mathrm{~L} / \mathrm{min}$ and a tank volume of $T_{V}$ in each tank $j$, hence bacteria leaves each scald tank at rate $W_{j} g / T_{V}$ (McCarthy et al., 2018). Similarly, the $\mathrm{pH}$ and temperature in each tank are denoted $\mathrm{pH}$ and $T^{j}$, respectively. Hence in scald tanks $j=1,2,3$ we have the following model equation describing the contamination dynamics in the scald water.

$W_{i}^{\prime}=\frac{1}{10^{3} T_{V}}\left(\sum_{i=1}^{N} k_{i}^{j} C_{i}\right)-\left(W_{i} \sum_{i=1}^{N} \beta_{i}^{j}\right)-\left(1+\alpha_{i}\right)\left(1+h_{w}\right) I_{w} W_{j}-\frac{g}{T_{V}} W_{j}$

\subsection{Complete model}

Combining equations ( 1 ) and (2) for $j=1,2,3$ and initial conditions reflecting the beginning of a scalding shift, the complete IBM becomes:

$$
\begin{aligned}
& C^{\prime}=\left\{\begin{array}{cc}
-\left(k_{i}^{1}+S_{i}^{1}+h_{S}\right) C_{i}-\left(k_{i}^{2}+S_{i}^{2}+h_{5}\right) & t_{i}^{\mathrm{I}} \leq t<\hat{t}_{i}^{3} \\
C_{i}-\left(k_{i}^{3}+S_{i}^{3}+h_{S}\right) C_{i} & \\
+10^{\prime} T_{V}\left(\beta_{i}^{1} W_{1}+\beta_{i}^{2} W_{2}+\beta_{i}^{3} W_{3}\right) & \text { for } i=1, \ldots, N \\
0 & \text { otherwise }
\end{array}\right.
\end{aligned}
$$

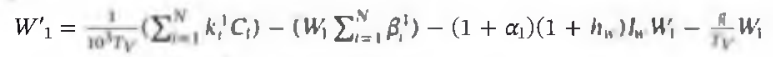

$$
\begin{aligned}
& W_{2}^{\prime}=\frac{1}{3 u^{3} T V}\left(\sum_{1=1}^{w} k_{1}^{2} C_{1}\right)-\left(W_{2} \sum_{1=1}^{N} \beta_{1}^{2}\right)-\left(1+c_{2}\right)\left(1+h_{w}\right) I_{w} W_{2}-\frac{g}{T_{V}} W_{2} \\
& W_{3}^{\prime}=\frac{1}{10^{3} T_{V}}\left(\sum_{i=1}^{N} k_{i}^{3} C_{i}\right)-\left(W_{3} \sum_{i=1}^{N} \beta_{i}^{3}\right)-\left(1+\alpha_{3}\right)\left(3+h_{14} I_{w} W_{1}-\frac{E}{N V} W_{3}\right.
\end{aligned}
$$

Initial conditions: Each carcass may have different initial contamination levels, which is one of the main advantages of the IBM. Let the pre-scald pathogen levels of carcass $i$ by $\sigma_{i}$ CFU. So we have the resulting initial condition $C_{i}(0)=\sigma_{i} \mathrm{CFU}$. For the water contamination levels, we start the scalding shift at $t=0$ and assume the scald tanks are clean and free of pathogens. In other words, we have $W_{1}(0)=W_{2}(0)=W_{3}(0)=0 \mathrm{CFU} / \mathrm{ml}$.

\subsection{Well-posedness}

To show that the model is well-posed, we first consider the linear system

$\frac{d x}{d t}=A(t) x(t)+v(t)$

where $x(t)$ and $v(t)$ are $n$-dimensional vector-valued functions and $A(t)$ is an $n \times n$ matrix. We make use of the following theorem from (Filipov, 1988).

Let all the elements of the matrix $A(t)$ and the vector-valued function $v(t)$ be summable (i.e. Lebesque integrable) on each segment contained in the interval $(a, b)$. Then for all $t_{0} \in(a, b)$ the solution of the system with an arbitrary initial condition $x\left(t_{0}\right)=x_{0}$ exists on the whole interval $(a, b)$ and is unique.

Let $(a, b)=\left(-1, t_{N}^{3}+1\right)$ and now we make use of the above theorem. As a result, we have existence and uniqueness of solutions of the scalding model (3) for $t=0 \mathrm{~min}$ to $t=i_{\mathrm{N}}^{-5} \mathrm{~min}$. That is, solutions exist from the beginning of the scalding process until the last carcass exits the last scald tank. Also, it may be easily shown that for nonnegative parameter values and initial conditions, solutions to the scald model (3) remain nonnegative.

\subsection{Parameter estimation}

Here we estimate transfer and inactivation parameters for the IBM for the specific pathogen $C$. jejuni. Scald model (3) is composed from three main types of mechanisms: (I) those that involve typical processing procedures for industrial scalding, (II) bacteria transfer between compartments and inactivation in each compartment, and (III) parameters associated with input contamination levels and within-flockprevalence. Parameters, along with relevant values/ranges, corresponding to Type I, Type II, or Type III mechanisms are categorized below.

\subsubsection{Type I parameters}

We assume a fixed mass $m_{\mathrm{Z}}(\mathrm{kg})$ for all incoming broiler carcasses. Here we have $m_{c}=2 \mathrm{~kg}$ as in (McCarthy et al., 2017, 2018). From a high-speed plant in Thailand, a clean water flow rate of $g=172 \mathrm{~L} / \mathrm{min}$ and tank size $T_{V}=5900$ liters are reported (Osiriphun et al., 2012). We then assume $T_{V_{j}}=5900$ liters and $\mathrm{g}_{l}=172 \mathrm{~L} / \mathrm{min}$ for all three stage tanks $j=1,2,3$.

\subsubsection{Type II parameters}

Bacteria shedding rate $k$ Estimates of bacterial shed rate were obtained in (Osiriphun et al., 2012) and a similar range also obtained in (McCarthy et al., 2018). We therefore fix $k_{i}^{j}=1.05 \mathrm{~min}^{-1}$ as found in (Osiriphun et al., 2012) for each bird $i$ in scald tank $j$. In other words, we assume that the rate of bacterial shedding into the scald water is the same in each tank.

Bacteria inactivation on carcass surfaces $S_{l}^{j}$

We estimate the thermal surface kill rate $S_{i}^{j}$ of $C$. jejuni by adopting the Bigelow model (Bigelow, 1921). The Bigelow model is typically expressed as $D(T)=D_{\text {ref }} 10^{-\left(T-T_{\text {ref }}\right) / z}$. To proceed, we fit the Bigelow model to six previously estimated inactivation rates from poultry scalding-specific experiments (Osiriphun et al., 2012). The resulting coefficients from curve fitting are $D_{\text {ref }}=1.85$ min, mean $z$-value $=16.06$ and $95 \% \mathrm{CI}$ for the $z$-value is $(8.48,23.64)$ using the reference temperature $54.15^{\circ} \mathrm{C}$. For details of this curve fitting process refer to Section 6.2 in the Appendix. We also note that $S_{i}^{J}=\ln (10) / D(T)$ when the $D$-values are converted to inactivation rate for use in scald model (1).

Organic material levels and $\mathrm{pH}$ indeed impact this kill rate (Berrang et al., 2011; Yang et al., 2001); however, the dominant factor determining the kill rate on carcass surfaces is scald water temperature. Note the kill rates yielded from fitting are similar to those synthesized in (Berrang et al., 2011; McCarthy et al., 2018; Yang et al., 2001). We estimate the chlorine's additive effect of inactivating pathogens on the carcass surface $h_{s}=[0.0067,0.023]$ using a control pathogen inactivation experiment conducted in tap water and also an experiment conducted in poultry process water (with an organic load) (Yang et al., 2001). In particular, D-values were reported for chlorine inactivation on chicken skin in tap water (control) and in poultry process water. The organic load buffers pathogen inactivation, hence we consider $h_{S}$ within a range derived from both experimental rates. One explanation for this reduced killing potential is due to inactivation of chlorine near the carcass surfaces by organic material (Yang et al., 2001). In the former 
case, we observe $D=73 \mathrm{~min}$ corresponding to $h_{S}=0.0231 / \mathrm{min}$ using the relationship $I=\ln (10) / D$. In the scalding water, we see $D=344$ min corresponding to $h_{S}=0.0067$ also using the same relationship between $D$-value and inactivation rate $I$. Hence we consider $h_{S}$ in the range $[0.0067,0.023] 1 / \mathrm{min}$.

C. jejuni inactivation in scald water We utilize a thermal inactivation model validated against experimental scald water data which accounts for $i) C$. jejuni strain, ii) variation in experimental data, and iii) high levels of organic material in scald water (developed in (McCarthy et al., 2018)). For each temperature and $\mathrm{pH}$ pair, this model gives us a range for the baseline kill rate in scald water $I_{w}$ accounting for these variations (McCarthy et al., 2018). The form of this inactivation model is $I_{w}(p H, T)=\frac{1,10}{D_{w}(p h, N)}$ where $D_{w}(p H, T)$ is fit for each individual $C$. jejuni strain $i$ :

$D_{w}(p H, T)=\hat{a} e^{-((p H-b) / \epsilon)} a_{i} e^{b_{i}\left(T-T_{\text {nef }}\right)}$

Where $\hat{a}, \hat{b}, \hat{c}$ are parameters relating the kill rate to $\mathrm{pH}$ and $a_{i}, b_{i}$ relate strain-specific inactivation with temperature. This model attributes a Gaussian relationship between $\mathrm{pH}$ and D-value and also an exponential relationship between D-value and temperature (McCarthy et al., 2018)

The percent increase of bacteria killing in scald water with the addition of $50 \mathrm{ppm}$ chlorine we estimate to be $h_{w}=0.59$ (Yang et al., 2001). We note that it is logical that $h_{w}>h_{s}$ since the contact of FC with pathogens in scald water is higher than contact with pathogens on carcass surfaces.

Buffering effects of organic material in scald water $\alpha_{j}$ Experimental data indicates that $C$. jejuni inactivation is reduced significantly in the presence of organic material (Yang et al., 2001), which decreases in each successive scald tank (Cason et al., 1999). To model these effects on bacteria killing in scald water, we essentially fit experimental data taken at various temperatures and in the presence of varying organic material levels (Yang et al., 2001). We invite the reader to see the details for this process in Appendix (Sec A.3). Recall $\alpha_{j}$ represents the percent increase in effective thermal kill rate in tank $j$ due to organic material levels. The results are $\alpha_{1}=0, \alpha_{2}=0.31, \alpha_{1}=0.56$, hence, in each successive tank the viable bacteria in scald water is killed more quickly.

Attachment to carcass surfaces $\beta$ We use laboratory scale experimental data to estimate the rate for which bacteria in scald water attaches to a carcass surface $\beta \in[0.001,0.0218] \mathrm{min}^{-1}$ (Lillard, 1986). We utilize a broiler chicken mass to surface area relationship for these calculations (United States Department of Agriculture, 1996). In addition to contact time we note that the attachment mechanism depends on temperature (NGUYEN et al., 2010) and pH (Nguyen et al., 2012); however, there is a lack of experimental data regarding these phenomena, so we do not precisely quantify the effects of these factors. For details of this parameter estimate, see Appendix A.4.

\subsubsection{Type III parameters: pre-scald carcass contamination and prevalence} levels

In practice, carcasses are rinsed and then samples are analyzed to estimate pathogen levels on the entire carcass. A minimum concentration of bacteria must be present for the experiment to yield an estimate, otherwise the pathogen is undetected and we say the carcass is under the limit of detection. If a carcass contains bacteria levels above the limit of detection, then we consider it $C$. jejuni positive. On the other hand, carcasses with $C$. jejuni levels below the limit of detection we say are $C$. jejuni negative.

We estimate the incoming carcass contamination for each bird with the following methodology $i$ ) a carcass may be $C$. jejuni negative or positive ii) the pathogen levels on incoming birds are set to match experimental levels estimated in (Berrang and Dickens, 2000). In particular, we assume that positive birds have $C$. jejuni levels which are normally distributed. The normal distribution captures the inherent variability in pre-scald pathogen levels on chickens and the general trend that bacteria levels may follow within a group (Berrang and Dickens, 2000; Seliwiorstow et al., 2015). Also, we assume that $C$. jejuni negative carcasses have uniformly distributed levels under the detection limit ( $<1000 \mathrm{CFU} /$ carcass in (Berrang and Dickens, 2000)). Since the pathogen levels on these carcass are not enumerable, hence there is no data supporting how these pathogen levels are distributed. Hence randomly assigning pre-scald levels for these carcasses is a natural choice. The detection limit is several orders of magnitude smaller than most positive carcasses, hence the $C$. jejuni negative birds should not have a large effect on system behavior. The percent of birds which are C. jejuni positive we refer to as the prevalence (or within-flock prevalence), which we denote $p$. We estimate $p=0.68$ using experimental Campylobacter data from many flocks on a United States farm (Berghaus et al., 2013). Since a typical broiler flock being processed is typically large (greater than 10,000 birds), we focus on the scalding process for a single flock (Berghaus et al., 2013).

\section{Simulation}

Here we provide a simulation scheme that we use for validation and application of the scald model (3) informed with parameters and initial conditions from Table 1 as outlined below.

\subsection{Simulation setups}

Note that all model parameter values in Table 1 are fixed values except for the bacteria kill rate in scald water $I_{w}$, and the attachment rate from scald water to carcass surfaces $\beta$, surface thermal kill rate $I_{c}$, and chlorine inactivation rate $h_{S}$. To explore these parameter ranges and their impact on post-scald contamination levels, we numerically solve model (3) twice according to setup I (low-risk) or II (high-risk) below:

\subsubsection{Setup (I)}

When $I_{i 1}$ is on the high end, $\beta$ is on the low end, $h_{S}$ is high, and $I_{c}$ is high, the carcass contamination levels are lowest (Fig. A5). Here the kill rate of the viable bacteria in the water is high combined with the relatively slow rate of attachment resulting in lowest net effects of crosscontamination. The results for this simulation are shown in the Appendix (Fig. A5).

\subsubsection{Setup (II)}

When $I_{w}$ is on the low end, $\beta$ is on the high end, $h_{S}$ is low, and $I_{c}$ is low, the post-scald carcass contamination levels are highest. Here the kill rate of bacteria in the scald water is low while $\beta$ is on high end; hence, attachment occurs more rapidly. This range of the parameter space yields the highest levels of cross-contamination. As a result, we numerically solve scald model (3) twice; one for each scenario described above.

\subsubsection{Monte Carlo simulations}

In addition to the low-risk and high-risk simulations, we perform uncertainty analyses in the form of Monte Carlo simulations. That is, we observe the changes in model output with respect to sampling different regions of the parameter space. In particular, we use Latin Hypercube Sampling to sample $I_{w}, \beta, I_{c}$, and $h_{S}$ from their respective ranges and numerically solve model (3) each time. Monte Carlo simulations are performed in Section 4.1, 4.2, and 4.3 and are shown in Figs. 1B, 2B and 2.

In the case of setup (I), setup (II) and the Monte Carlo simulations described above, $I_{w}, \beta, I_{c}$, and $h_{S}$ are now known, remaining model parameters for scald model (3) are known and come from Table 1. The initial pathogen levels on each carcass are sampled from a distribution as described in Section 2.5.3. Scald model (3) is now informed with a complete set of fixed model parameters and initial conditions for $W_{j}$ for $j=1,2,3$ and $C_{i}$ for $i=1,2, . . N$. We numerically compute solutions for 
Table 1

Parameter values and ranges found in Section 2.5 informing the scald model (3). Simulation for the complete IBM determined by these parameters is carried out in Section 3.

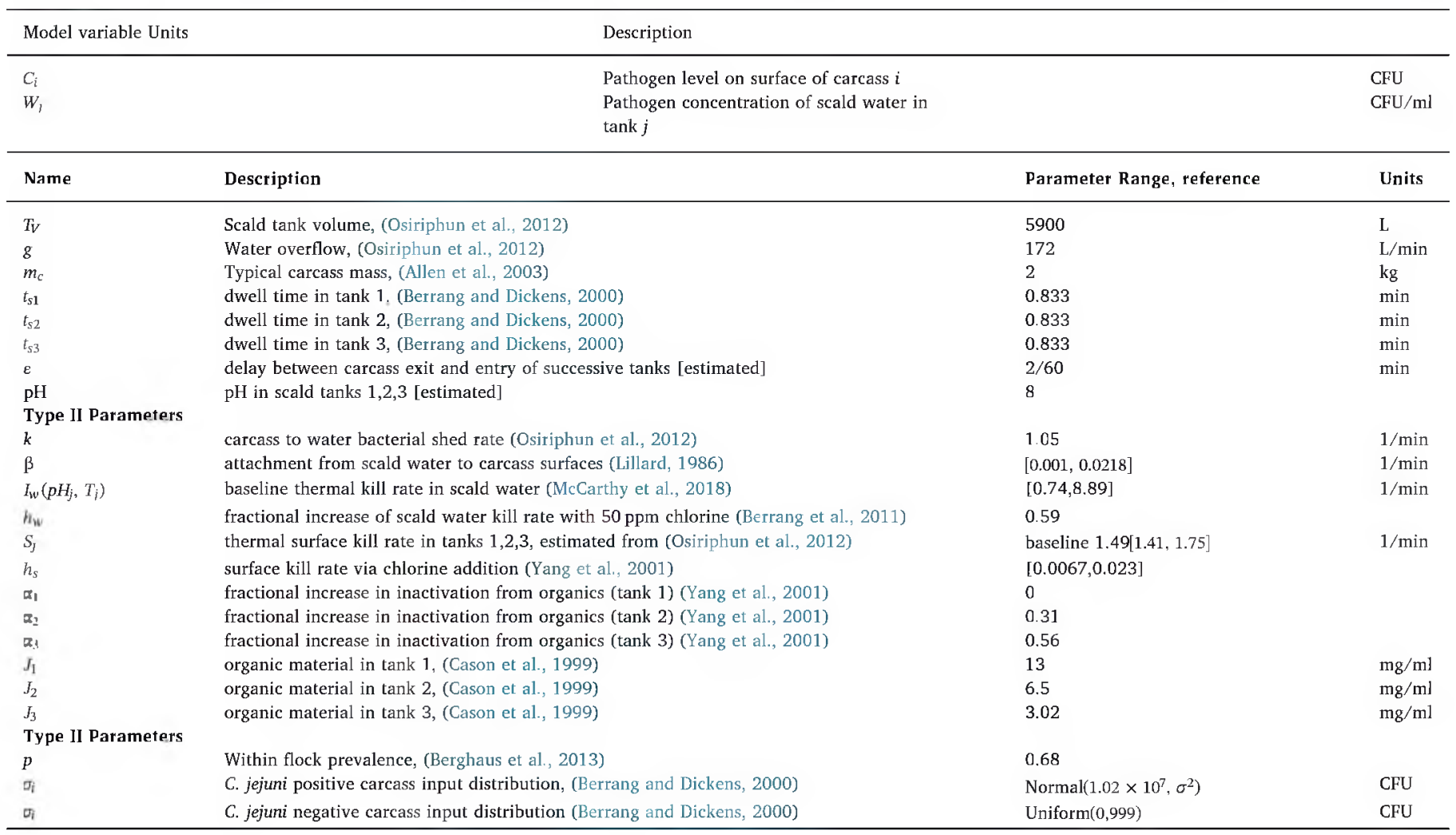
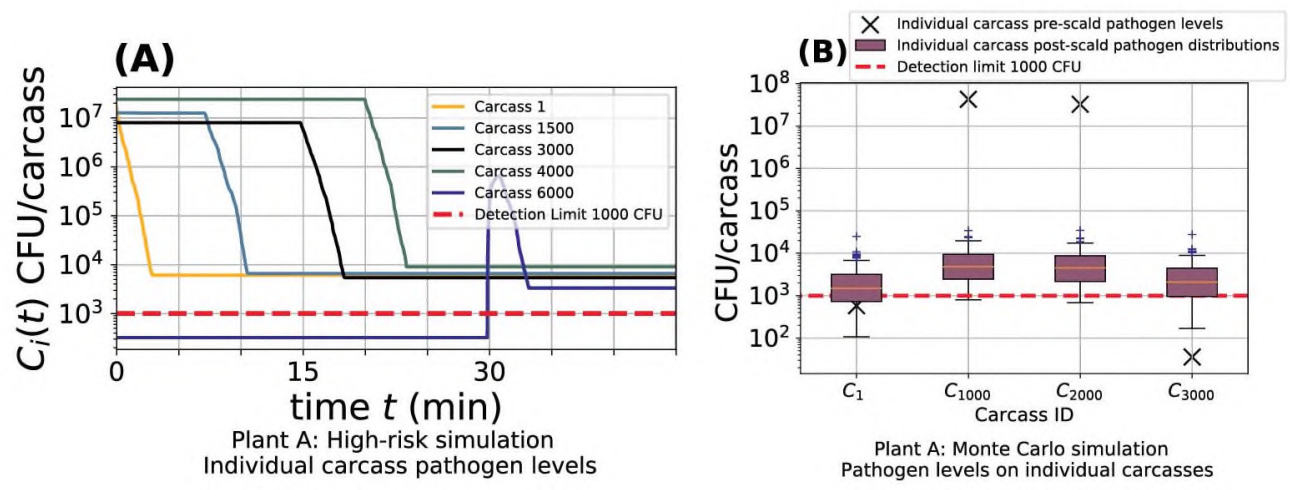

Fig. 1. Pathogen levels on individual broiler carcasses. A) Time dynamics of individual carcass pathogen levels during scalding in a high-risk scenario (corresponding to setup II: $I_{w}$ low, $\beta$ high, $h_{S}$ low, and $I_{s}$ low). Each curve and color is associated with pathogen levels on a single carcass. For example, carcass \#3000 enters (light blue curve) enters the scalder at about $15 \mathrm{~min}$ and leaves the scalder $3.33 \mathrm{~min}$ later. B) Monte Carlo simulations depicting the distributions of post-scald pathogen levels for individual carcasses. Here, each simulation yields a single post-scald pathogen level on each carcass and corresponds to a single parameter sample set of $I_{c}, \beta, h_{S}$, and $I_{w}$. We display post-scald distributions shown for carcass \#1, \#1000, \#2000, and \#3000 in the scalding process.

this system of $\mathrm{N}+3$ ordinary differential equations using the Matlab function ode45, which is an implementation of the Runge-Kutta method. Similar results may be obtained using a variety of software and numerical differential equation solution methods.

\subsection{Model forward validation}

Here we describe the forward validation process of scald model (3) against industrial processing data from Berrang and Dickens (2000). We inform the model parameters in the same setting to carcass pre-scald contamination levels (Type III) as well as processing configurations (Type I) to replicate those in (Berrang and Dickens, 2000). The pre- scald pathogen levels $\sigma_{i}$ (incoming levels on each bird $i$ ) reflect the prescald sample mean and variance found in (Berrang and Dickens, 2000). Just 30 birds were sampled in (Berrang and Dickens, 2000), hence we use prevalence from a more comprehensive Campylobacter survey including on-farm levels on 658 birds (Berghaus et al., 2013). This figure may more accurately depict the prevalence on a typical farm in the United States. We then numerically solve the scald model (3) twice, in accordance with setup (I) and setup (II) described above. Using two numerical solutions of the scald model, we obtain a range for the mean output bacteria level $\mu \in\left[1.15 \times 10^{4}, 2.6 \times 10^{4}\right] \mathrm{CFU} /$ carcass which captures the experimental mean of $\mu=1.89 \times 10^{4} \mathrm{CFU} /$ carcass (Berrang and Dickens, 2000). The simulation results are shown in Fig. 
(A)

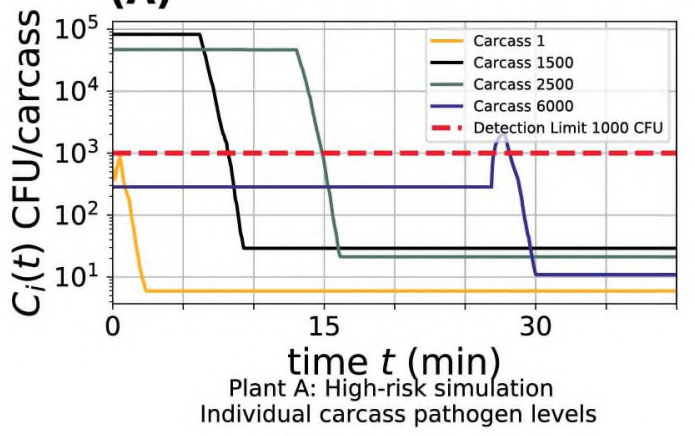

$X$ Individual carcass pre-scald pathogen levels

(B)

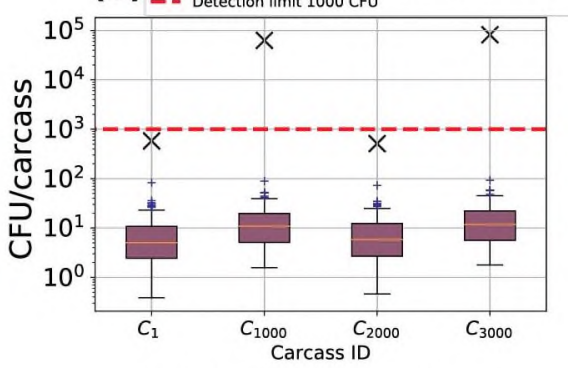

Plant A: Monte Carlo simulation Pathogen levels on individual carcasses

Fig. 2. Pathogen levels on individual broiler carcasses. A) Time dynamics of individual carcass pathogen levels during scalding in a high-risk scenario corresponding to setup II ( $I_{c}$ low, $L$ low, $\beta$ high, and $h_{S}$ low). Each curve and color is associated with pathogen levels on a single carcass. For example, carcass \#1500 enters (black curve) enters the scalder at about $8 \mathrm{~min}$ and leaves the scalder $3.33 \mathrm{~min}$ later. B) Monte Carlo simulations depicting the distributions of post-scald pathogen levels for individual carcasses. A and B) Illustrate how lowering pre-scald mean levels and prevalence may dramatically reduce individual post-scald pathogen levels below the limit of detection. The pathogen levels on individual carcasses $\# 1, \# 1000, \# 2000$, and $\# 3000$ are shown and may be compared with the levels in Fig. 1, observing the lower mean pathogen levels in this scalding scenario.

A5 in the Appendix. Note we carry out the estimation of parameters related to bacteria transfer and inactivation (Type II parameters) without using industrial slaughterhouse data and we validate the model against (Berrang and Dickens, 2000). A key feature of the scald model (3) is that it simplifies many complicated phenomena to a mathematically tractable form using few transfer and inactivation parameters which we can reliably estimate.

\section{Scald model application}

Here we show how our scalding framework may be applied by using poultry plant scalding process specifications, namely scalding temperature and $\mathrm{pH}$. Effectively the scald model (3) gives us a metric for systematically comparing various input prevalence and pathogen levels for weighing control strategies and guiding management for pathogen levels on the farm. To demonstrate the use of this quantitative link we provide model simulations corresponding to various pre-scald contamination levels. We also explore the implications of this link in terms of risk assessment and scenario analysis in Section 4.3.4.

USDA-FSIS performance standards for Campylobacter on broiler carcasses are in terms of prevalence after chilling (Food Safety US Department of Agriculture and Inspection Service, 2015). More specifically, carcasses are sampled from a poultry processor weekly and microbiological analysis is performed. If greater than 8 of 51 of these post-chill carcass samples are Campylobacter positive, then the processor does not meet the performance standard for this period (Food Safety US Department of Agriculture and Inspection Service, 2015). Here we demonstrate how scald model (3) may be used to help processors meet these standards. In particular, we illustrate how the prescald distribution of pathogens on carcasses impacts the output carcass prevalence for varying pre-scald pathogen levels. The power here is that the model may inform maximum allowable pre-scald prevalence and pathogen levels in accordance with these standards through numerical experimentation. Here we work with the scald model applied to the 2015 USDA-FSIS Campylobacter performance standards. In Section 4.3.4 we discuss how to apply this model to other microbial performance standards.

\subsection{Model applications to a specific industrial poultry processor in Canada}

We apply the scald model to a specific processing plant in Canada whose scalding configurations were provided to us by the Public Health Agency of Canada and Canadian Poultry and Egg Processors Council. We refer to this specific plant as Plant A (as in (McCarthy et al., 2018)). These scalding configurations come from a recent survey and hence may represent a typical high-speed industrial processing scenario. The scalding process configuration of plant $\mathrm{A}$ is as follows: the $\mathrm{pH}$ in all three scald tanks is 9 , the temperature in scald tanks 1,2 , and 3 are $T_{1}=51.66, T_{2}=53.33, T_{3}=58.89^{\circ} \mathrm{C}$ respectively, and carcasses have dwell times $t_{s 1}=1 \mathrm{~min}, t_{s 2}=1 \mathrm{~min}, t_{s 3}=1.33 \mathrm{~min}$ in tanks 1 ,2, and 3 .

We simulate scalding shifts for Plant $A$ with the above process parameters and all other parameters remain the same as in Section 3.2. In other words, we "numerically scald" the same carcasses in a series of numerical experiments. Numerical results of the low- and high-risk simulations are included in Table 2. We also illustrate the time dynamics of pathogen levels on individual carcasses using the high-risk setup II in Fig. 1A. Lastly, the results of Monte Carlo simulation are shown in Fig. 1B. In the Monte Carlo simulations we provide 100 realizations of the scald model (3) to simulate the post-scald distributions of $C$. jejuni on individual carcasses. In Fig. $1 \mathrm{~A}$ and $\mathrm{B}$, we see that post-scald pathogen levels are similar regardless of pre-scald levels. Even more, most individual carcass pathogen levels approach the mean post-scald over all carcasses. The post-scald prevalence is above $8 / 51 \approx 0.16$, hence Plant A may be at risk of failing USDA-FSIS Campylobacter performance standards (Food Safety US Department of Agriculture and Inspection Service, 2015). Further reduction in pathogen levels may be required in later processing stages with this processing configuration.

\subsection{Altering pre-scald C. Jejuni prevalence and pathogen levels}

Bacterial contamination on the broiler surfaces is carried from the farm to transport and subsequently into the slaughterhouse. We now illustrate how the scald model may be applied to weigh these various scenarios. Specifically, we look at how post-scald pathogen levels are affected by adjusting the incoming prevalence $p$ and mean input level $\mu$ $\mathrm{CFU} /$ carcass. We modify the pre-scald pathogen distribution on carcasses as follows: The $C$. jejuni positive carcasses are contaminated with an average of $\mu=10^{5} \mathrm{CFU} /$ carcass and also the within-flock prevalence is reduced from $68 \%$ to $30 \%$. This reduced prevalence replicates $30 \%$ pre-scald Campylobacter prevalence found in Denmark according to the European Food Safety Authority's analysis of the 2008 EU baseline survey for Campylobacter in broilers (European Food Safety Authority, 2010).

We present the same set of simulation configurations as in Section 4.1 with this augmented pre-scald distribution. Results of the low-risk and high-risk simulations are included in Table 2. Time dynamics of pathogen levels on individual carcasses using high-risk setup I are shown in Fig. 2A. Also, Monte Carlo simulation results are shown in Fig. 2B.

We see altering the pre-scald prevalence and mean pathogen level 
Table 2

Results of simulations for the scald model (3) in Plant BD and Plant A.

\begin{tabular}{|c|c|c|c|c|c|c|}
\hline Processor & Setup' & Input prevalence & Pre-scald mean ${ }^{2}$ & Output prevalence & Post-scald mean ${ }^{2}$ & USDA-FSIS Perf. Standard ${ }^{3}$ \\
\hline Plant BD ((Berrang and Dickens, 2000)) & I & $68 \%$ & 7.18 & $99 \%$ & 4.06 & Fail \\
\hline Plant BD ((Berrang and Dickens, 2000)) & II & $68 \%$ & 7.18 & $100 \%$ & 4.42 & Fail \\
\hline Plant A & $\mathrm{I}$ & $68 \%$ & 7.18 & $0 \%$ & 2.3 & Pass \\
\hline Plant A & II & $68 \%$ & 7.18 & $100 \%$ & 3.7 & Fail \\
\hline Plant A & $\mathrm{I}$ & $30 \%$ & 5 & $0.0 \%$ & 2.3 & Pass \\
\hline Plant A & II & $30 \%$ & 5 & $0.0 \%$ & 1.3 & Pass \\
\hline
\end{tabular}

${ }^{1}$ Setup I corresponds to a low-risk simulation $\left(I_{w}\right.$ high, $\beta$ low, $I_{c}$ high, and $h_{S}$ high) and setup II corresponds to a high-risk simulation $\left(I_{w}\right.$ low, $\beta$ high, $I_{c}$ low, and $h_{S}$ low).

${ }^{2} \log _{10}$ CFU/carcass

${ }^{3}$ If more than 8 of 51 post-chill carcass samples are Campylobacter positive, then the processor does not meet the 2015 USDA-FSIS Campylobacter performance

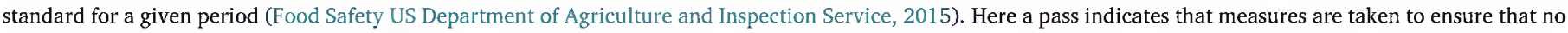

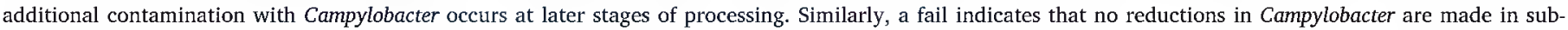
sequent processing.

reduces the post-scald pathogen levels on nearly all carcasses below the detection limit of $1000 \mathrm{CFU} /$ carcass $(\approx 0 \%$ post-scald prevalence). In particular, the altered pre-scald distribution brings Plant A into passing territory for the 2015 USDA-FSIS Performance standards (Food Safety US Department of Agriculture and Inspection Service, 2015). Hence it may be possible that small changes in policy and management on the farm may correspond to very different levels post-scald and post-processing. Hence decision-making regarding processing compliance with performance standards may be guided with the scald model (3). In Section 4.3 we look more closely at post-scald prevalence and how it depends on pre-scald carcass contamination levels, revealing that the effects of the mean of prescald pathogen levels dominates influence of the pre-scald prevalence.

\subsection{A closer look at post-scald prevalence levels}

Recall that the estimates for the $C$. jejuni kill rate in scald water $I_{w}$ and attachment rate to carcasses $\beta$ are in terms of particular ranges. In the previous simulations (Figs. $1 \mathrm{~A}$ and $2 \mathrm{~A}$ ) we choose these parameters according to the lowest and highest opportunity for cross-contamination (high-risk setup I and low-risk setup II). To gain insights into the typical output contamination levels, we perform Monte Carlo simulations as outlined in Section 3. We repeat this process for pre-scald prevalence over the full spectrum between $0 \%-100 \%$ and for mean values on positive carcass $\mu=10^{6}, \mu=10^{7} \mathrm{CFU} /$ carcass. In particular, we see a threshold pre-scald prevalence level that separates the prescald levels into two distinct regions: one which post-scald prevalence levels are typically below the 2015 USDA-FSIS Campylobacter performance standard and another where post-scald prevalence are typically above the performance standard (Food Safety US Department of Agriculture and Inspection Service, 2015). Above a higher input prevalence all carcasses will be $C$. jejuni positive. The power here is that the model may inform maximum allowable prevalence and input mean levels for processors to meet performance standards. Here when $\mu=10^{6}$ $\mathrm{CFU} /$ carcass we see that the post-scald prevalence is most frequently $0 \%$ (Fig. 3A); however, few parameter sets yield high post-scald prevalence (Fig. 3A). In particular, when $p<0.50$ then typically Plant A will pass the USDA-FSIS Campylobacter performance standard assuming no additional contamination with Campylobacter occurs at later stages of processing (Food Safety US Department of Agriculture and Inspection Service, 2015). On the other hand, notice that when $\mu=10^{7} \mathrm{CFU} / \mathrm{car}$ cass, typically the post-scald prevalence is above the performance standard limit when input prevalence is above $10 \%$ (Fig. 3B). However there are exceptions at all pre-scald prevalences which correspond to $0 \%$ post-scald prevalence due to high inactivation rates and limited opportunity for cross-contamination. Depicted is 100 simulations for each input prevalence, exploring the parameter space with Latin $\mathrm{Hy}$ percube Sampling. For details regarding Latin Hypercube Sampling see
(Marino et al., 2008) (see Fig. 3).

We now turn to the high-risk scenario (setup II) and look at how post-scald prevalence depends on pre-scald contamination. We conduct model simulations over a wide range of pre-scald configurations: $10^{1} \leq \mu \leq 10^{9} \mathrm{CFU} /$ carcass and $0-100 \%$ prevalence $p$ (Fig. 4). We see interesting behavior when we vary pre-scald configurations in these ranges. In particular, the pre-scald input mean $C$. jejuni levels $\mu$ dominates prevalence $p$ in terms of affecting post-scald prevalence. We also see the emergence of a sharp transition from $0 \%$ to $100 \%$ post-scald prevalence as the pre-scald mean increases above $10^{5} \mathrm{CFU}$. The key here is that with only process operating procedures, this threshold and risk map may be generated with the scald model (3).This threshold mean contamination level may be of use for guiding maximum allowable pathogen levels on the farm, which we discuss further in Section 4.3.4.

\subsubsection{Scald model dynamics}

The scald model (3) has a convenient mathematical form allowing for simple analysis. In fact, pathogen levels on each negative and positive carcasses may be approximated with explicit expressions. The idea is that we can predict pathogen levels on carcasses in each individual tank and repeat for all three tanks. We leverage these approximate solutions to develop rules of thumb for mitigating crosscontamination and discuss further implications in Section 4.3.4.

Similarly note that when $W(l)=w_{j}$ for $j=1,2,3$ and constants $w_{j}, C_{i}$ may be solved explicitly in each tank. Hence, if we have time series data for concentrations for $W_{j}(t)$ then carcass contamination may be inferred if their pre-scald levels are known. Similarly, ranges for $W_{j}(t)$ may be used to explore output pathogen levels. Also, we may weigh the efficacy of altered water recycling strategies on post-scald pathogen levels. We discuss potential applications for the model for use with emerging sensor technologies in Section 4.3.4.

\subsubsection{Maximum $\log _{10}$ reduction}

Lastly, we introduce a metric to quantify the maximum possible reduction of pathogen levels on carcasses during scalding. In the absence of cross-contamination, that is either bacterial attachment from scald water $\beta=0$ or $W_{1}^{\prime}(t)=W_{2}(t)=W_{3}(t)=0 \mathrm{CFU}$, pathogen levels on carcasses will be at its lowest. We then denote the maximum $\log _{10} r e$ duction of a carcass by

$M L R=t_{s}^{1}\left(k_{1}^{1}+h_{s}+S_{i}^{1}\right)+t_{s}^{2}\left(k_{i}^{2}+h_{s}+S_{i}^{2}\right)+t_{s}^{3}\left(k_{t}^{3}+h_{s}+S^{3}\right)$.

Note carcasses entering the scald tank with pathogen levels above $M L R$ cannot become decontaminated. Here MLR depends only on dwell time in each scalding tank and scald water temperature. With our parameter estimates in Section 2.5, the MLR may be easily calculated. See Section 4.3 .4 for the details. 


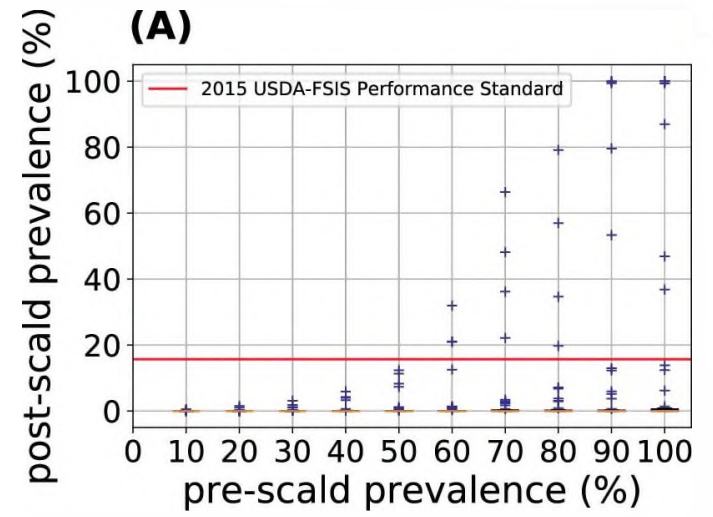

Post-scald prevalence vs. pre-scald prevalence mean input $\mu=10^{6} \mathrm{CFU} /$ carcass

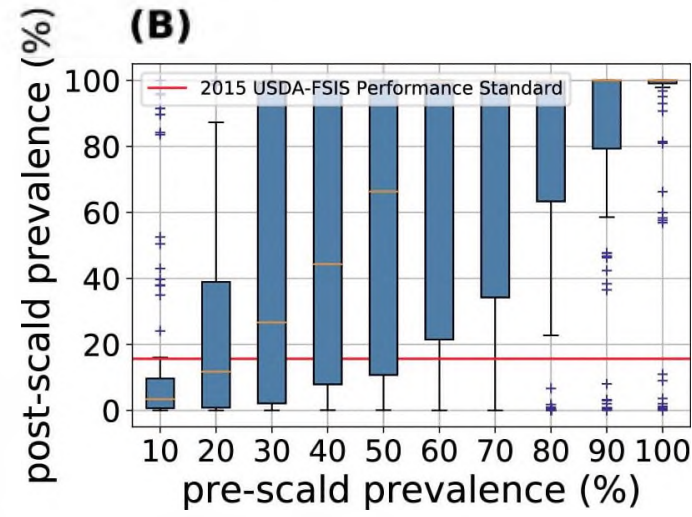

Post-scald prevalence vs. pre-scald prevalence mean input $\mu=10^{7} \mathrm{CFU} / \mathrm{carcass}$

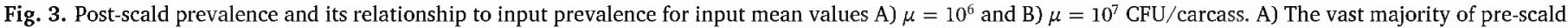

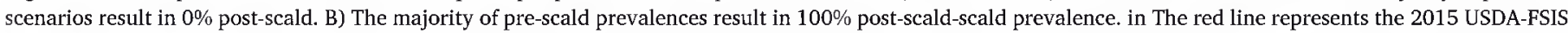

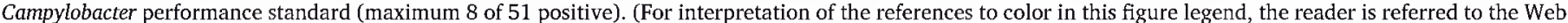
version of this article.)

\subsubsection{Control guidance}

In the scald model ( 3 ) the change in bacteria level on a given carcass is determined by two rates: the decay rate on the carcass $k+h_{s}+S_{j}$ and the rate bacteria attaches from the scald water $10^{3} T_{V} \beta$. In other words $\left(k+h_{5}+S_{1}^{l}\right)^{-1}$ is the average time in minutes that bacteria remains on the carcass and $\left(10^{3} T_{V} \beta\right)^{-1}$ is the average time it takes for a single bacteria in scald water to attach to a given carcass. Essentially the following control quantity $C_{\text {, }}^{*}$ captures these two characteristic time scales. $C_{j}^{*}$ may be thought of as an attracting state which changes in time.

$C_{j}^{*}=C_{j}^{*}\left(W_{j}(t)\right)=\frac{10^{3} T^{\prime} \beta W_{j}(t)}{k+h_{s}+S_{1}^{\prime}}$

The following two mathematical results relate the control quantity $C_{\text {, }}^{*}$ to prevalence, namely whether or not positive carcasses stay positive and negative carcasses stay negative.

i) A C. jejuni positive carcass $i$ entering a scald tank $j$ will remain $C$. jejuni positive in tank $j$ if

$c_{j}^{*}>$ detection for $t \in\left[t_{i}{ }^{i}, \hat{t}_{i}^{j}\right]$.

ii) A C. jejuni positive negative $i$ entering a scald tank $j$ will remain $C$. jejuni negative in tank $j$ if
$C_{j}^{*}<$ detection for $t \in\left[t_{i}^{j}, \hat{t}_{i}^{j}\right]$.

Proof: Please refer to Section 6.5 for proofs of results $i$ ) and $i i)$.

These results $i$ ) and ii) give relationships between detection level and $W(t)$, since we have estimates of the remaining parameters. In particular, $i$ ) and ii) give conditions on scald water concentration which ensure that positive carcasses remain positive and negative carcasses remain negative in a given scald tank. Hence we may use $C_{j}^{*}$ to find a maximum concentration of pathogens in the scald water to prevent negative carcasses from being contaminated. One result of this condition is that pathogen levels in the third and final scald tank $W_{3}$ must consistently remain low to obtain post-scald prevalence below $100 \%$.

\subsubsection{Risk assessment and risk management}

Typical laboratory testing takes several days to obtain bacteria counts from samples. However, on-line biosensors and potentially automated methods are emerging, reducing the time required to retrieve sample bacteria counts (Massad-IvanirGiorgi et al., 2016). These on-line sensors may be implemented to sample scald process water. Currently the fastest sensors take roughly $30 \mathrm{~min}$ to estimate pathogen levels from a water sample. However as this detection time decreases, it may allow for the development of automated alert systems in which groups of highly contaminated birds may be located before they leave the processing plant. As we discussed in Section 4.3.1, the scald model (3) may be used to infer pathogen levels on carcasses if the levels of bacteria in

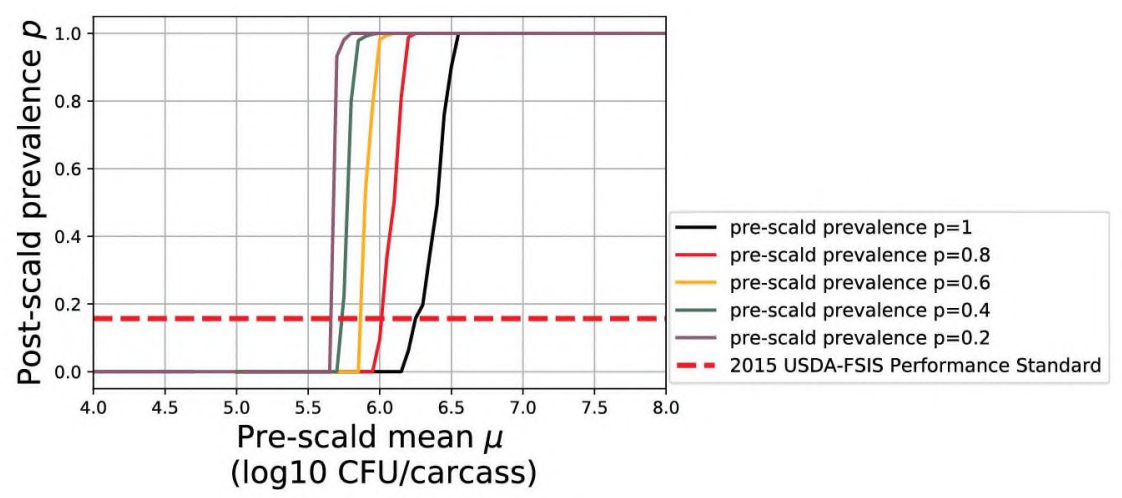

Plant A: High-risk simulation Individual carcass pathogen levels

Fig. 4. A, B) High-risk simulation (Setup II: low $I_{w}$, high $\beta$, low $I_{c}$, low $h_{S}$ ) illustrating the effects of pre-scald mean and prevalence on post-scald prevalence. The prescald mean has a greater impact than pre-scald prevalence in terms of influence on post-scald prevalence. Also, we see threshold mean values between roughly $\mu=5.5$ and $6.5 \log 10 \mathrm{CFU} /$ carcass where the post-scald prevalence sharply increases. 
the scald water and pre-scald pathogen levels are known. Similarly, equation (2) with discrete-time measurements of the bacterial concentration in the scald water along with $\mathrm{pH}$ levels, scalding temperature, and water flow rates can be used to estimate the average pathogen counts over all carcasses in each scald tank. Hence our parameter estimates, modeling framework, and tools we develop may be used to more rapidly (and automatically) infer average pathogen levels on carcasses. Overall, there is an emerging space for potential application synthesizing mathematical modeling, automated on-line sampling methods, and (bio)sensor networks. Furthermore, this application space becomes more broad with improving technology; namely, the decreased bacterial enumeration time of sensors.

The scald model and framework developed herein may assist in the policymaking and risk assessment processes. For instance, given a target post-scald $C$. jejuni count and/or prevalence the scald model may guide maximum allowable levels on the farm by only informing the model with scald water temperatures, $\mathrm{pH}$, and carcass dwell times. For instance, if a carcass enters the scalder with pathogen levels above the maximum $\log _{10}$ reduction then they will remain contaminated above detection levels. Scalding prepares carcasses for defeathering and later evisceration and chilling which are all major sites of cross-contamination (FAO/WHO, 2009). Hence a potential strategy for mitigating foodborne illness risk is bringing all carcasses below the detection limit in the scalding stage, as scalding occurs early in processing. The scald model may help guide processors and policymakers with such decisionmaking. Moreover, the model was designed specifically for this purpose. In terms of risk analysis, the scald model (3) fills in an important component of a poultry consumer process model. The present authors have developed a similar individual-carcass model has been developed for the poultry chilling operation (McCarthy et al., 2017). The defeathering and evisceration may also be approached with similar individual-carcass modeling techniques to aid in understanding and mitigating cross-contamination. At present time models for defeathering and evisceration are less tractable than the scalding and chilling processes.

In this work, we focus on standards set by the FSIS-USDA which is in terms of Campylobacter prevalence. We note that other similar national performance standards exists and the scald model and techniques illustrated herein may be applied similarly to assist with decision-making. For instance, New Zealand has experienced high incidence of Campylobacteriosis and has more elaborate performance standards for poultry consisting of three components: alerts associated with highly contaminated birds, moving window targets, and quarterly mean values (Massad-IvanirGiorgi et al., Segal). With the scalding framework we develop, the procedure we present may easily be augmented to make recommendations for these standards as well as providing worldwide utility. More particularly, given process specifications and pre-scald counts, numerical experiments which illuminate precisely the expected number of birds above critical pathogen levels, test a moving target window over all carcasses. Throughout the paper we refer to risk of USDA-FSIS failure in terms of prevalence post-scald. It is possible that pathogens are introduced onto carcasses via cross-contamination from equipment or viscera rupture during evisceration, raising post-chill prevalence. Prevalence may also be reduced in subsequent stages changing the plant's pass or fail status.

\section{Conclusions}

The scald model (3) provides a quantifiable link between pre-scald pathogen levels, scalding processing parameters, and post-scald pathogen levels. The model we present may be a useful tool for risk assessment where experiments are costly, time consuming, or impractical. The general modeling framework and technique presented may be used to inform quantitative microbial risk assessment (QMRA) models with mechanistic detail. In particular, given pre-scald pathogen levels on carcasses and scalding configurations (e.g., scalding temperature, $\mathrm{pH}$ levels, etc.) the post-scald levels can be predicted using our scald model and fed into subsequent components of the QMRA model. In particular, post-scald levels may be used as inputs in the defeathering stage of a QMRA model, which may then be fed into the evisceration stage, and so on. Hence, this general framework may be used to determine best practices and policy in accordance with compliance standards in the United States (Food Safety US Department of Agriculture and Inspection Service, 2015) and European Union Reg. No. 2073/2005 (Althaus et al., 2017). Furthermore, many scenarios (e.g., logistic slaughter) may be evaluated in terms of the output contamination and risk they pose. For instance, influences on the farm (e.g., flock prevalence, within flock prevalence, incoming contamination levels) as well as processing configuration may also be weighed.

Future directions The model may be adapted to account for changing organic material levels, which would give insights for the time of the scalding shift for which pathogen levels may be highest or cross-contamination is most likely. We predict that the organic material levels impact the inactivation of bacteria toward the end of a scalding shift as there is a constant influx of organic material and relatively little outflow due to water recycling. The current model is set up for the end of day organic levels which pose the highest threat.

Overall, in this work we use data from various sources and experiments to inform model parameters based on availability. We synthesized the bacterial attachment rate to carcasses $\beta$ using laboratory scale data collected from excised poultry skin (Lillard, 1986). This attachment rate is not well understood and may be influenced by many factors including scald water $\mathrm{pH}$ and temperature (Lillard, 1986; NGUYEN et al., 2010). Laboratory scale experiments which give more information as attachment rates change with temperature, $\mathrm{pH}$, and other factors would help clarify understanding this rate of attachment. Also, industrial experiments which give pathogen levels for an individual carcass before and after scalding would give further insight on this attachment rate. We note that Markov Chain Monte Carlo (MCMC) techniques may be used to estimate Type II parameters describing transfer and inactivation. This methodology may give a more realistic picture of the transfer and inactivation time scales in the model. These statistical parametrization methods may be used to, for example, determine if the scalding process enhances or inhibits bacterial attachment.

The high variation of thermal kill rate in scald water with respect to the C. jejuni strain, especially at high temperatures, yields corresponding high variation in post-scald prevalence due to vast differences of cross-contamination effects felt during processing. Obtaining a narrower range for these rates with further inactivation experimentation would clarify model prediction. Then, having strain specific thermal inactivation information as well as specific strain presence in each processor may be useful for control purposes in each plant. Also, complete processing configurations such as line speeds, clean water flow rates, scald tank volumes, contamination levels, organic material levels are convenient for informing Type II transfer and inactivation parameters in such mechanistic models. Wider availability of these items may also assist in model parametrization and increase predictive power.

In this work, the scald model is formulated with several assumptions. First, we assume that cross-contamination does not occur via physical contact between carcasses in the scalding tanks. Also we incorporate several well-mixing assumptions in the model, $i$ ) bacteria attaches to all carcasses at the same rate and ii) bacteria is well-mixed in the scald water, i.e. the bacterial concentration in the scald water is uniform over the entire scald tank. The results relating the control parameter $C_{j}^{*}$ and $C$. jejuni levels on individual carcasses in Section 4.3.3 are mathematical consequences of these assumptions. We note that when the spatial uniformity in bacteria in scald water assumption is relaxed then these results may require adjustment. Realistically, highly contaminated carcasses may contribute more to the pathogen levels of their neighbors in the scald tank; however, this is not considered in the 
present model. Measurements of bacterial concentrations at different locations (e.g. the scalder entrance and exit) may indicate that space should be accounted for. It is also possible that the counterflow introduces a bacterial gradient as well as organic material gradient in the scald water in each tank. However, at the present time this data is not available.

\section{Acknowledgements}

We obtained plant processing data obtained from the Public Health
Agency of Canada and Canadian Poultry and Egg Processors Council from a 2012-2013 poultry processor survey, first referenced in (McCarthy et al., 2018). This research was funded by a contract between the Laboratory for Industrial and Applied Mathematics and the Public Health Agency of Canada. Jianhong Wu is also supported by the Natural Sciences and Engineering Research Council of Canada (Grant number: 105588-2011) and the Canada Research Chairs Program (Grant number:230720). We would also like to thank two anonymous reviewers for their careful readings and suggestions which have improved the manuscript.

\section{A. Appendix}

\section{A.1. Effects of organic material levels on carcass inactivation}

C. jejuni inactivation rates were recovered by comparing bacterial populations after heating in tap water (control) and scalding water after $10 \mathrm{~h}$ of continuous processing (Yang et al., 2001). Inactivation rates in scald water were significantly reduced in the experiments conducted in presence of the scald water (Yang et al., 2001). We suggest that the observed inactivation buffering effect of scald water is also dampened by the changes in water chemistry, namely the $\mathrm{pH}$ of scald water. The levels of $C$. jejuni recovered from chicken skins were higher in the presence of organic material as opposed to those in tap water (Yang et al., 2001). However this may be due to altered pH of scald water (McCarthy et al., 2018). Since tap water is neutral $\mathrm{pH}$ and scald water is acidic in the absence of additives due to organic material presence. We expect a similar buffering effect of bacteria would be found on broiler carcass skins, where organic material levels play a dominant role. However, the effect of $\mathrm{pH}$ dominates the effects of organic material levels on inactivation on carcass skins. Similar rates of pathogen inactivation are estimated using all known data sources (McCarthy et al., 2018; Osiriphun et al., 2012; Yang et al., 2001). Overall, we see that organic material may have a stronger influence than pH of kill rate on carcass skins. These experiments suggest that the effects of organic material on inactivation are in fact small compared to those from scald water $\mathrm{pH}$ (Yang et al., 2001). With all these factors in mind, as expected, the temperature is the dominant player in determining inactivation rates in scald water and on carcasses.

\section{A.2. Details of estimating the pathogen kill rate on carcass surfaces}

From the Bigelow model we have $D(T)=D_{\text {ref }} 10^{-\frac{1}{2}\left(T-T_{\text {ref }}\right)}$ (Gaillard et al., 1998). To inform this inactivation model $D(T)$, we use industrial-scale scalding experiments (Osiriphun et al., 2012). Scalding shifts were conducted at several temperatures and carcasses were sampled for subsequent microbiological analysis (Osiriphun et al., 2012). With the estimated $C$. jejuni counts on carcasses, estimates for carcass surface inactivation rates were provided for each temperature (Osiriphun et al., 2012). Here we use standard least square curve fitting to fit $D(T)$ to this data with reference temperature $T_{r e f}=54.15^{\circ} \mathrm{C}$. We use Matlab's curve fitting package cftools for the least squares fitting and find resulting coefficients $D_{r e f}$ and $z-$ values mean $(95 \% \mathrm{CI})$ to be $z=16.06(8.48,23.64)$. For use in the scald model $(1)$, we convert $D(T)$ in units (min) to inactivation rate $(1 / \mathrm{min})$ using the relationship $I(T)=\ln (10) / D(T)$. In other words, we find $S_{i}^{j}=I(T)$. In Monte Carlo simulations (Figs. $1 \mathrm{~B}$, $2 \mathrm{~B}$ and $3 \mathrm{~A}$, and 3B) we consider the variation in $I_{c}$ as a result of this uncertainty in the $z$-value.

\section{A.3. Details of estimating influence of organic material on kill rate in scald water}

Here we elaborate on the parameter estimation process for $\alpha$, the percent increase of kill rate in scald water from reduced organic material levels. The scald water inactivation parameter $I_{w}(p H, T)$ is fit to agree with data taken in scald water containing $13 \mathrm{~g} / 1$ solids (McCarthy et al., 2018; Humphrey and Lanning, 1987). As a result of these buffering effects, this inactivation rate of free bacteria in scald water is higher with less organic material than the reference level of $J=13 \mathrm{~g} / \mathrm{l}$. We model these effects by fitting a surface $\phi(T, J)$ to the $C$. jejuni inactivation data reported for $50^{\circ} \mathrm{C}$ and $55^{\circ} \mathrm{C}$. In each temperature cross-section (that is, for a fixed $J, \phi(T, J)$ is exponential in temperature. We then join these temperature crosssections with a line from zero organic load to high levels of organic material.

We find the resulting surface

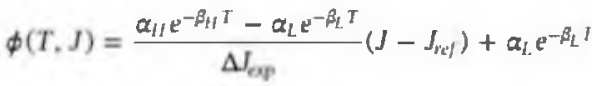

To estimate the buffering effects in each tank $\alpha_{j}$ we first set $\Delta J_{e x p}=13 \mathrm{~g} / \mathrm{l}$ and $J_{r e f}=0$ to replicate experimental settings (Yang et al., 2001). Now, we use $\phi(T, J)$ to obtain an estimate on $\alpha$ for any corresponding scalding temperature $T$ and organic load level $J$. For organic load levels in each tank, we set $J_{1}^{*}=13 \mathrm{~g} / \mathrm{l}$ as experimentally measured in (Humphrey and Lanning, 1987). Since organic material levels are typically halved in sequential scald tanks we estimate $J_{2}^{*}=6.5 \mathrm{~g} / 1$ and $J_{3}^{*}=3.25 \mathrm{~g} / \mathrm{l}$ (Cason et al., 1999). The resulting percentage increases in bacterial kill rate to be $\alpha_{1}=0$, $\alpha_{2}=0.31, \alpha_{3}=0.56$ in scald tanks 1,2 , and 3 , respectively.

\section{A.4. Attachment to carcass surfaces $\beta$}

To estimate the range for this attachment rate, we use laboratory-scale experimental data (Lillard, 1986). In this experiment, excised chicken carcass skins were immersed in solution and exposed to known $S$. Typhimurium concentrations (Lillard, 1986). We then use the reported pathogen levels recovered from carcass skins after immersion for $30 \mathrm{~s}$ and $30 \mathrm{~min}$ and the equation $C^{\prime}=10^{3} \beta T_{V} W$ from scald model (3). From this equation and assuming $W$ is constant over the course of the experiment, we have $C\left(t_{f}\right)-C\left(t_{0}\right)=10^{3} \beta T_{V} W\left(t_{f}-t_{0}\right)$ which relates $\beta$ and experimental settings. Now, using the experimental data we find $\beta$ corresponding to the slow and fast kinetics above. To convert the units of $\beta$ from attachment rate per $12 \mathrm{~cm}^{2}$ to a whole broiler carcass, we use the following mass-to-surface area relationship 
Total Surface Area $(\mathrm{cm}$ squared $)=0.87 w+635$

where $w$ is weight of a carcass in $g$ (United States Department of Agriculture, 1996). The pathogen levels recovered after $30 \mathrm{~s}$ give an estimate of the upper bound on $\beta$ (fast kinetic) and 30 min pathogen levels immersion reports to estimate the lower bound on $\beta$ (slow kinetic). We then estimate attachment rate $\beta=[0.001,0.021] 1 / \mathrm{min}$.

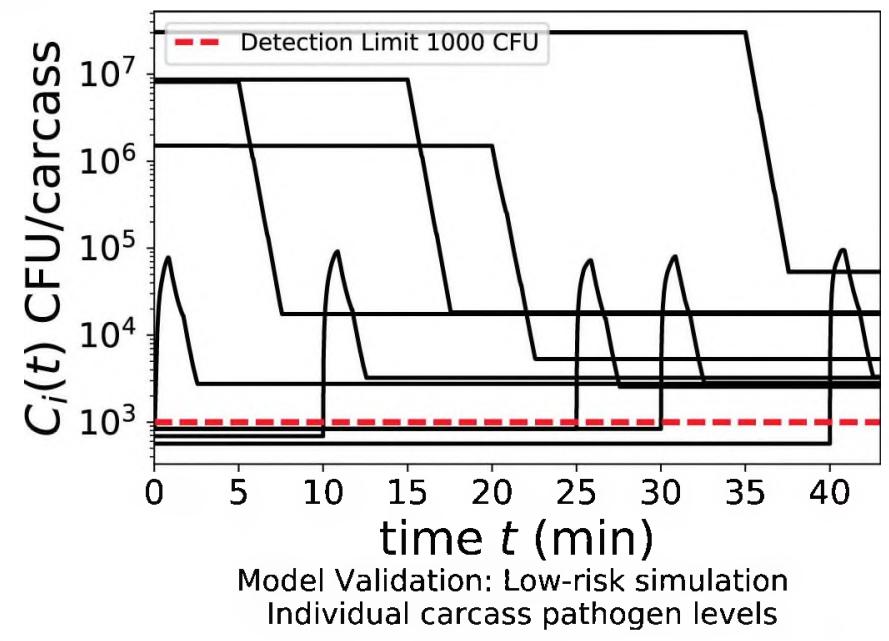

Fig. A5. C. jejuni levels on individual broiler carcasses. Solutions correspond to numerical solutions of scald model (3) with parameters from Table 1. A) Depict Setup (I): $\left(I_{n}\right.$, high end, $\beta$ low end, $h_{S}$ high, $I_{C}$ high) results. Here the mean post-scald $C$. jejuni level on broiler carcasses is $\mu=1.15 \times 10^{4} \mathrm{CFU}$ and nearly all carcasses end up contaminated above the detection level of $1000 \mathrm{CFU} /$ carcass ( $99 \%$ prevalence).

\section{A.5Proofs of mathematical results in Section 4.3 .3}

i) A C. jejuni positive carcass $i$ entering a scald tank $j$ will remain $C$. jejuni positive in $\operatorname{tank} j$ if

$C_{j}^{*}>$ detection for $t \in\left[t_{i}^{j}, i_{i}^{j}\right]$.

Proof: Let $L=\inf \left\{C_{j}^{*}: t \in\left[t_{i}^{j}, \hat{t}_{i}^{j}\right]\right\}$. Hence we have $C_{j}^{*} \geq L$ and therefore $W(t) \geq\left(k_{i}^{j}+S_{i j}\right) L /\left(10^{3} T_{V} \beta_{j}^{j}\right)$ for $t \in\left[t_{i}^{j}, \hat{t}_{i}^{j}\right]$. Now, the contamination level on carcass $i$ changes in tank $j$ is given by Equation (1). Combining the preceeding bound on $W(l)$ as well as Equation (1) we have $C^{\prime}{ }_{i} \geq 0$ when $C=L$.

$C_{i}^{\prime}=-\left(k_{i}^{j}+S_{i}^{j}\right) C_{i}+10^{3} T_{V} \beta_{i}^{j} W_{j}(t) \geq-\left(k_{i}^{j}+S_{i}^{j}\right) C_{i}+10^{3} T_{V} \beta_{i}^{j} \frac{\left(k_{i}^{j}+S_{i}^{j}\right) I}{10^{3} T_{V} \hat{\beta}_{i}^{j}}=0$.

Since $C\left(t_{i}^{j}\right)>$ detection we havev $C(t)_{l} \geq$ detection $t \in\left[t_{i}^{j}, \dot{t}_{i}^{j}\right]$ and therefore carcass $i$ remains $C$. jejuni positive.

ii) A C. jejuni positive negative $i$ entering a scald tank $j$ will remain $C$. jejuni negative in $\operatorname{tank} j$ if

$C_{j}^{*}<$ detection, for $t \in\left[t_{i j}, \hat{t}_{j i}\right]$.

Proof: Let $M=\sup \left\{C_{j}^{*}: t \in\left[t_{i}^{j}, \hat{t}_{i}^{j}\right]\right\}$. Hence we have $C_{j}^{*} \leq M$ and therefore $W(t) \leq\left(k_{i}^{j}+S_{i}^{j}\right) M /\left(10^{3} T_{V} \beta_{i}^{j}\right)$ for $t \in\left[t_{j i} i_{j i}\right]$. Now, the contamination level on carcass $i$ changes in tank $j$ is given by Equation (1). Combining the preceeding bound on $W(t)$ as well as Equation (1) we have $C^{\prime}{ }_{i} \leq 0$ when $C=M$.

$C_{1}^{\prime}=-\left(k_{1}^{\prime}+S_{i}^{\prime}\right) C_{1}+10^{3} T_{i} \beta_{i}^{\prime} W_{j}(1) \leq-\left(k_{i}^{\prime}+S_{i}^{\jmath}\right) C_{1}+10^{3} T_{V} \beta_{i}^{\prime} \frac{\left(k_{i}^{j}+S_{i}^{\prime}\right) M}{10^{3} T_{V} \beta^{\prime}}=0$

Since $C\left(t_{i}^{\prime}\right)<$ detection, we have $C(t), \leq$ detection $\iota \in\left|t_{j j}, t_{j i}\right|$ and therefore carcass $t$ remains $C$. jejuni negative in tank $j$.

\section{References}

Allen, V.M., Hinton, M.H., Tinker, D.B., Gibson, C., Mead, G.C., Wathes, C.M., 2003. Microbial cross-contamination by airborne dispersion and contagion during defeathering of poultry. Br. Poult. Sci. 44 (4), 567-576.

Althaus, Denise, Zweifel, Claudio, Stephan, Roger, 2017. Analysis of a poultry slaughter process: influence of process stages on the microbiological contamination of broiler carcasses. Ital J Food Saf 6 (4).

Berghaus, R.D., Thayer, S.G., Law, B.F., Mild, R.M., Hofacre, C.L., Singer, R.S., 2013 Enumeration of salmonella and campylobacter spp. in environmental farm samples and processing plant carcass rinses from commercial broiler chicken flocks. Appl. Environ. Microbiol. 79 (13). 4106-4114.

Berrang, M.E., Dickens, J.A., 2000. Presence and level of campylobacter spp. on broiler carcasses throughout the processing plant. J. Appl. Poult. Res. 9 (1), 43-47.

Berrang, M.E., Windham, W.R., Meinersmann, R.J., 2011. Campylobacter, Salmonella, and Escherichia coli on broiler carcasses subjected to a high ph scald and low ph postpick chlorine dip. Poultry Sci. 90 (4), 896-900.

Bigelow, W.D., 1921. The logarithmic nature of thermal death time curves. J. Infect. Dis.
528,536 .

Cason, J.A., Whittemore, A.D., Shackelford, A.D., 1999. Aerobic bacteria and solids in a three-tank, two-pass, counterflow scalder. Poultry Sci. 78 (1), 144-147.

Christine, K., Olson, Ethelberg, Steen, Wilfrid van Pelt, Tauxe, Robert V., 2008. Epidemiology of Campylobacter jejuni infections in industrialized nations. In: Campylobacter, third ed. American Society of Microbiology, pp. 163-189.

European Food Safety Authority, 2010. Analysis of the baseline survey on the prevalence of campylobacter in broiler batches and of campylobacter and salmonella on broiler carcasses, in the eu, 2008-part b: analysis of factors associated with campylobacter colonisation of broiler batches and with campylobacter contamination of broiler carcasses; and investigation of the culture method diagnostic characteristics used to analyse broiler carcass samples. EFSA Journal 8 (8), 1522.

FAO/WHO, 2009. Risk Assessment of Campylobacter Spp. In Broiler Chickens: Technical Report.

Filipov, A.F., 1988. Differential Equations with Discontinuous Righthand Sides. SpringerScience + Business Media, Dordrecht.

Food Safety US Department of Agriculture and Inspection Service, 2015. Changes to the salmonella and campylobacter verification testing program: proposed performance standards for salmonella and campylobacter in not-ready-to-eat comminuted chicken 
and Turkey products and raw chicken parts and related agency verification procedures and other changes to agency sampling. Fed. Regist. 80, 3940-3950.

Gaillard, S., Leguerinel, I., Mafart, P., 1998. Model for combined effects of temperature, $\mathrm{ph}$ and water activity on thermal inactivation of bacillus cereus spores. J. Food Sci. $63,887-889$.

Humphrey, T.J., Lanning, D.G., 1987. Salmonella and Campylobacter contamination of broiler chicken carcasses and scald tank water: the influence of water ph. J. Appl. Bacteriol. 63 (1), 21-25.

Kirk, Martyn D., Pires, Sara M., Black, Robert E., Caipo, Marisa, Crump, John A Devleesschauwer, Brecht, Dopfer, Dorte, Fazil, Aamir, Fischer-Walker, Christa L., Hald, Tine, et al., 2015. World health organization estimates of the global and regional disease burden of 22 food borne bacterial, protozoal, and viral diseases, 2010: a data synthesis. PLoS Med. 12 (12), e1001921.

Lillard, H.S., 1986. Distribution of "attached" Salmonella Typhimurium cells between poultry skin and a surface film following water immersion. J. Food Prot. 49 (6), $449-454$.

Marino, Simeone, Hogue, lan B., Ray, Christian J., Kirschner, Denise E., 2008. A methodology for performing global uncertainty and sensitivity analysis in systems biology. J. Theor. Biol. 254 (1), 178-196.

Massad-lvanir, Naama, Giorgi, Shtenberg, Raz, Nitzan, Gazenbeek, Christel, Dries, Budding, Bos, Martine P., Segal, Ester, 2016. Porous silicon-based biosensors: towards real-time optical detection of target bacteria in the food industry. Sci. Rep. 6 . 38099.

Naama Massad-Ivanir, Giorgi Shtenberg, Nitzan Raz, Christel Gazenbeek, Dries Budding, Martine P Bos, and Ester Segal. Mpip. Sci. Rep.

McCarthy, Zachary, Smith, Ben, Fazil, Aamir, Wu, Jianhong, Ryan, Shawn D., Munther, Daniel, 2017. Individual based modeling and analysis of pathogen levels in poultry chilling process. Math. Biosci.

McCarthy, Zachary, Smith, Ben, Fazil, Aamir, Wu, Jianhong, Ryan, Shawn D., Munther, Daniel, 2018. Ph dependent $\mathrm{c}$. jejuni thermal inactivation models and application to poultry scalding. J. Food Eng. 223 (1-9).

Miıllner, Petra, Julie, M., Collins-Emerson, Midwinter, Anne C., Carter, Philip, Simon, E., Spencer, F., Peter van der Logt, Steve Hathaway, Nigel, P., French, 2010. Molecular epidemiology of campylobacter jejuni in a geographically isolated country with a uniquely structured poultry industry. Appl. Environ. Microbiol. 76 (7), 2145-2154.

Nguyen, Vu Tuan, Turner, Mark S., Dykes, Gary A., 2010. Effect of temperature and contact time on campylobacter jejuni attachment to, and probability of detachment from, stainless steel. J. Food Prot. 73 (5), 832-838.

Nguyen, Vu Tuan, Fegan, Narelle, Turner, Mark S., Dykes, Gary A., 2012. Role of attachment to surfaces on the prevalence and survival of Campylobacter through food systems. J. Food Prot. 75 (1), 195-206.

Osiriphun, Sukhuntha, Tuitemwong, Pravate, Koetsinchai, Woranut, Tuitemwong, Kooranaee, Erickson, Larry E., 2012. Model of inactivation of Campylobacter jejuni in poultry scalding. J. Food Eng. 110 (1), 38-43.

Seliwiorstow, Tomasz, Bare, Julie, Damme, Inge Van, Uyttendaele, Mieke, De Zutter, Lieven, 2015. Campylobacter carcass contamination throughout the slaughter process of campylobacter-positive broiler batches. Int. J. Food Microbiol. 194, 25-31.

Suzuki, Hodaka, Yamamoto, Shigeki, 2009. Campylobacter contamination in retail poultry meats and by-products in Japan: a literature survey. Food Control 20 (6), 531-537.

United States Department of Agriculture, 1996. Nationwide Broiler Chicken Baseline Data Collection Program.

Yang, Hong, Li, Yambin, Johnson, Michael G., 2001. Survival and death of Salmonella Typhimurium and Campylobacter jejuni in processing water and on chicken skin during poultry scalding and chilling. J. Food Prot. 64 (6), 770-776 